\title{
Evaluation of the Use of Ketamine for Acute Pain in the Emergency Department at a Tertiary Academic Medical Center
}

\author{
Nahal Beik ${ }^{1}$, Katelyn Sylvester ${ }^{1}$, Megan Rocchio' ${ }^{1}$ Michael B. Stone ${ }^{2}$ \\ ${ }^{1}$ Department of Pharmacy, Brigham and Women's Hospital, Boston, USA \\ ${ }^{2}$ Department of Emergency Medicine, Brigham and Women's Hospital, Boston, USA \\ Email: "nbeik@partners.org
}

Received 25 November 2015; accepted 10 January 2016; published 13 January 2016

Copyright (C) 2016 by authors and Scientific Research Publishing Inc.

This work is licensed under the Creative Commons Attribution International License (CC BY). http://creativecommons.org/licenses/by/4.0/

(c) (i) Open Access

\section{Abstract}

Introduction: At subdissociative doses of $0.1-0.5 \mathrm{mg} / \mathrm{kg}$, ketamine provides effective analgesia when used alone or as an adjunct to opioid analgesics without causing cardiovascular or respiratory compromise. Ketamine is a beneficial analgesic agent in the emergency department (ED), particularly in patients with opioid-resistant pain or polytrauma patients who are hemodynamically unstable. Purpose: The purpose of this study was to evaluate current practice and describe clinical outcomes associated with the use of low-dose ketamine for acute pain in the ED. Methods: Adult patients receiving ketamine were retrospectively evaluated between March 1, 2012 and March 31, 2013. Patients were included if they were ordered for ketamine in the ED to treat acute pain. Outcomes included dose administered, cumulative doses, concurrent opioid administration, and any efficacy or adverse events documented after the administration of ketamine. Continuous variables are reported as mean (standard deviation [SD]) or median (interquartile range [IQR]). Results: A total of 46 patients were evaluated for inclusion. Of the 25 patients included, 38 doses of ketamine were documented. The mean age was 41 years old with $64 \%$ of the patients being female. The average initial ketamine dose was $0.12 \pm 0.06 \mathrm{mg} / \mathrm{kg}$ and $8(32 \%)$ patients received multiple doses of ketamine (1.5 \pm 0.8 doses per patient). Ketamine was added to opioid therapy in 23 (92\%) patients. Pain scores decreased post administration of ketamine from $10(9$ - 10) to 5 (4 - 7). Adequate pain relief was documented in $11(44 \%)$ patients (felt comfortable going home); partial pain relief was noted in $5(20 \%)$ patients; $3(12 \%)$ patients reported no pain relief; $3(12 \%)$ patients were able to have a procedure done, and efficacy was not documented in $3(12 \%)$ patients. Anxiety and agitation were documented in $2(8 \%)$ patients. No adverse outcomes were documented in $84 \%$ of patients. Conclusion: Administration of low-dose ketamine for acute pain in the ED demonstrated improvement in patients' pain scores with minimal documented adverse outcomes.

\footnotetext{
*Corresponding author.
} 


\section{Keywords}

\section{Ketamine, Acute Pain, Emergency Department}

\section{Introduction}

Pain remains one of the most common chief complaints for adults presenting to emergency departments (ED) nationwide. Chest pain, abdominal pain, back pain, headache and injuries are cited as the top five reasons for ED presentation based on national ED survey data from 2006 and 2011 [1] [2]. These same data report that approximately half of all patients presenting to the ED describe their pain as moderate (25\%) or severe (20.4\%) [1]. Depending on the nature and severity of pain, the standard of care for initial treatment of pain in the ED involves using non-specific analgesics such as a non-steroidal anti-inflammatory agent or an opioid [3].

For some patients, complex past medical histories and concomitant disease states render standard approaches inadequate to treat their pain. In such cases, an alternative analgesic agent such as ketamine should be considered. Ketamine has been shown to be a beneficial analgesic agent in the ED, particularly in patients with opioid-resistant pain (sickle-cell crisis, chronic pain such as cancer and palliative care) or trauma patients who are hemodynamically unstable [3] [4]. The use of ketamine in the ED has been viewed as favorable by both patients and ED physicians [5].

Ketamine is a potent noncompetitive N-methyl-D-aspartate (NMDA) antagonist, best known for its anesthetic properties. At standard doses, it produces profound and rapid anesthesia and analgesia with minimal to no respiratory or hemodynamic compromise and has a predictable duration of action with a relatively short elimination half-life [6] [7]. At subdissociative doses of $0.1-0.5 \mathrm{mg} / \mathrm{kg}$, ketamine provides effective analgesic properties, when used alone or as an adjunct to opioid analgesics, with less pronounced psychoactive effects [5] [8]. Additionally, ketamine has a wide margin of safety minimizing the concern for accidental overdose [6]. For these reasons, low-dose ketamine has gained favor as an option for pain management in the ED as reflected by the increased volume of research published in emergency medicine literature over recent years.

At our institution, intravenous (IV) ketamine use is restricted by indication and service, and may be ordered and administered by ED attending physicians for analgesia associated with uncontrolled, incident pain [9]. The purpose of this study was to evaluate current practices and prescribing patterns of ketamine in our ED and to describe clinical outcomes associated with the use of low-dose ketamine for acute pain in the ED.

\section{Methods}

This was a single-center, retrospective, descriptive analysis of clinical practice of adult patients admitted to our ED who received ketamine for acute pain. Our institutional review board reviewed and approved the study protocol prior to data collection.

Patients were identified between March 1, 2012 and March 31, 2013 via a report generated from the ED Order Entry system. To be included in the analysis, patients had to be $>18$ years of age and received at least one dose of ketamine for acute pain. Patients were excluded if they received ketamine in the ED for a non-pain indication or if ketamine was ordered but not administered.

Investigators collected data retrospectively, and demographic data collected included age, gender, ethnicity, comorbidities, ketamine indication, home opioid use, and baseline vitals. Outcomes assessed included doses administered, total cumulative doses, concurrent opioid administration, additional therapies used for the treatment of acute pain, and any documented efficacy and safety endpoints in patient charts. Efficacy endpoints were defined as documentation of decreased pain scores and patient reported pain relief after ketamine administration. We assessed safety endpoints by reviewing notes in the patient chart for documentation of patient reported events directly related to ketamine administration as well as medication records for the use of benzodiazepines post ketamine administration as a surrogate for serious behavioral disturbance.

\section{Results}

During the study timeframe, 46 patients were evaluated for inclusion. Twenty-one patients were excluded: ketamine was ordered and discontinued (7 patients); ketamine was used during rapid sequence intubation (8 pa- 
tients); ketamine was used for deep procedural sedation (6 patients). A total of 25 patients (54.3\%) were included in the final analysis. Demographic information is outlined in Table 1. The majority of our patients was opioid tolerant (80\%) and presented to the ED with a chief complaint of pain (92\%). The top three pain presentations were traumatic pain related to motor vehicle crash or fall (30.4\%), abdominal pain (21.7\%) and oncology pain (17.4\%). Ketamine was prescribed by 10 different emergency medicine attendings.

The mean initial ketamine dose was $0.12 \pm 0.06 \mathrm{mg} / \mathrm{kg}$ and 8 patients (32\%) received multiple doses of ketamine (1.5 \pm 0.8 doses per patient). Dosing regimens are outlined in Table 2. Ketamine was used as the initial therapy in 5 patients (20\%). Ketamine was used concomitantly with opioids in 23 patients (92\%).

\section{Table 1. Patient demographics.}

\begin{tabular}{|c|c|}
\hline Variable & Patients $(\mathrm{n}=25)$ \\
\hline Age, years ${ }^{*}$ & $41 \pm 11$ \\
\hline Gender-male ${ }^{* *}$ & $9(36.0)$ \\
\hline Weight, $\mathrm{kg}^{*}$ & $76.2 \pm 20$ \\
\hline \multicolumn{2}{|l|}{ Ethnicity $^{* *}$} \\
\hline White & $19(82.6)$ \\
\hline Hispanic & $3(13.0)$ \\
\hline African American & $1(4.3)$ \\
\hline \multicolumn{2}{|l|}{ Comorbidities $^{* *}$} \\
\hline Hypertension & $9(36.0)$ \\
\hline End-stage renal disease & $1(4.0)$ \\
\hline Congestive heart failure & $1(4.0)$ \\
\hline Diabetes & $3(12.0)$ \\
\hline Malignancy & $7(28.0)$ \\
\hline Tobacco use & $9(36.0)$ \\
\hline Alcohol/illicit drug use & $11(44.0)$ \\
\hline \multicolumn{2}{|l|}{ Indication $^{* *}$} \\
\hline Pain & $23(92.0)$ \\
\hline Traumatic pain & $7(30.4)$ \\
\hline Abdominal pain & $5(21.7)$ \\
\hline Oncology pain & $4(17.4)$ \\
\hline Incision and drainage/abscess & $3(13.0)$ \\
\hline Lower extremity pain & $2(8.7)$ \\
\hline Back pain & $1(4.3)$ \\
\hline Neuropathic pain & $1(4.3)$ \\
\hline Sickle cell crisis & $1(4.0)$ \\
\hline Back spasms & $1(4.0)$ \\
\hline Home opioid use ${ }^{* *}$ & $20(80.0)$ \\
\hline \multicolumn{2}{|l|}{ Baseline vitals $^{*}$} \\
\hline Blood pressure, mmHg & $135.8 / 78 \pm 20.5 / 19.8$ \\
\hline Heart rate, beats per minute & $95.4 \pm 16.8$ \\
\hline Temperature, F & $97.8 \pm 1.1$ \\
\hline Respiratory rate, breaths per minute & $18.5 \pm 2.6$ \\
\hline Oxygen saturation, \% & $97.5 \pm 1.9$ \\
\hline Admitted & $15(60.0)$ \\
\hline Attending physicians prescribing & 10 \\
\hline
\end{tabular}


Table 2. Ketamine therapy.

\begin{tabular}{|c|c|}
\hline Variable & Patients $(n=25)$ \\
\hline Ketamine doses administered & 38 \\
\hline Initial ketamine dose, $\mathrm{mg} / \mathrm{kg}^{*}$ & $0.12 \pm 0.06$ \\
\hline Multiple doses administered—patients ${ }^{* *}$ & $8(32.0)$ \\
\hline Mean doses per patient, mg* & $1.5 \pm 0.8$ \\
\hline Total ketamine administered, mg & 520.6 \\
\hline Cumulative dose per patient, $\mathrm{mg}^{*}$ & $13.2 \pm 5.2$ \\
\hline Ketamine as initial therapy $^{* *}$ & $5(20)$ \\
\hline \multicolumn{2}{|l|}{ Concomitant therapies $^{* *}$} \\
\hline Opioids & $23(92)$ \\
\hline Benzodiazapines $\wedge$ & $7(28)$ \\
\hline Prior to ketamine & $5(71.4)$ \\
\hline Simultaneous administration & $1(14.3)$ \\
\hline Post ketamine & $1(14.3)$ \\
\hline Other" & $2(8)$ \\
\hline \multicolumn{2}{|l|}{ Pain scores } \\
\hline Pre ketamine $\mathrm{e}^{\ddagger}$ & $10(9-10)$ \\
\hline Post ketamine ${ }^{\ddagger}$ & $5(4-7)$ \\
\hline
\end{tabular}

In terms of efficacy, 11 patients (44\%) reported adequate pain relief and 5 patients (20\%) reported partial pain relief, and 3 patients (12\%) reported no pain relief. Efficacy was not documented in 3 patients (12\%), and the remaining 3 patients (12\%) reported tolerable relief (Figure 1).

Subsequent reports of anxiety and agitation were documented on 2 patients (8\%) and 1 patient received a benzodiazepine post ketamine administration. There was no documentation of adverse outcomes in $84 \%$ of patients (Figure 2). Of the 5 patient self-reported adverse events documented, there was 1 instance of feeling weird, 1 instance of feeling anxious, and 1 patient was still in pain. Although there was no documentation of unstable vital signs, there were 2 documented cases of stable vital signs. Of the 25 patients treated with ketamine for pain, 10 patients were discharged from the ED to home (40\%).

\section{Discussion}

The mainstay of treatment for severe acute pain in the ED is IV opioids, and although opioids can provide effective and rapid pain relief, doses needed to achieve adequate pain relief may result in over sedation and respiratory depression [10]. Ketamine is a recognized anesthetic and short-acting analgesic that has been in use for over 30 years [11]. It has a remarkable safety profile and is one of the world's most commonly used agents for procedural sedation and general anesthesia [11]. Since ketamine is an NMDA receptor antagonist, it is a logical choice for controlling pain as well as inducing anesthesia [6] [7]. At subdissociative doses of $0.1-0.5 \mathrm{mg} / \mathrm{kg}$, ketamine provides effective analgesic properties with little to no dissociative effects [5] [8]. Studies evaluating the benefit of low-dose ketamine for acute pain have produced favorable results for this indication, however, optimal dosing, specific patient populations, and additional efficacy and safety outcomes (e.g. single bolus vs. repeat dosing, need for rescue analgesia) have not been evaluated [4] [5] [8] [10]-[13].

Low-dose ketamine therapy was studied by Beaudoin, et al. [10], evaluating 60 adult patients with acute pain who presented to the ED. Patients were randomized to receive low-dose ketamine as an adjunct to morphine versus standard care with morphine alone. The dosing for ketamine was either $0.15 \mathrm{mg} / \mathrm{kg}$ or $0.3 \mathrm{mg} / \mathrm{kg}$. The investigators of the study found that low-dose ketamine is a viable analgesic adjunct to morphine for the treatment of moderate to severe acute pain based on patient-reported pain scores, and that the dosing of $0.3 \mathrm{mg} / \mathrm{kg}$ is possibly more effective than $0.15 \mathrm{mg} / \mathrm{kg}$, but may be associated with minor adverse events, such as dysphoria and dizziness. 


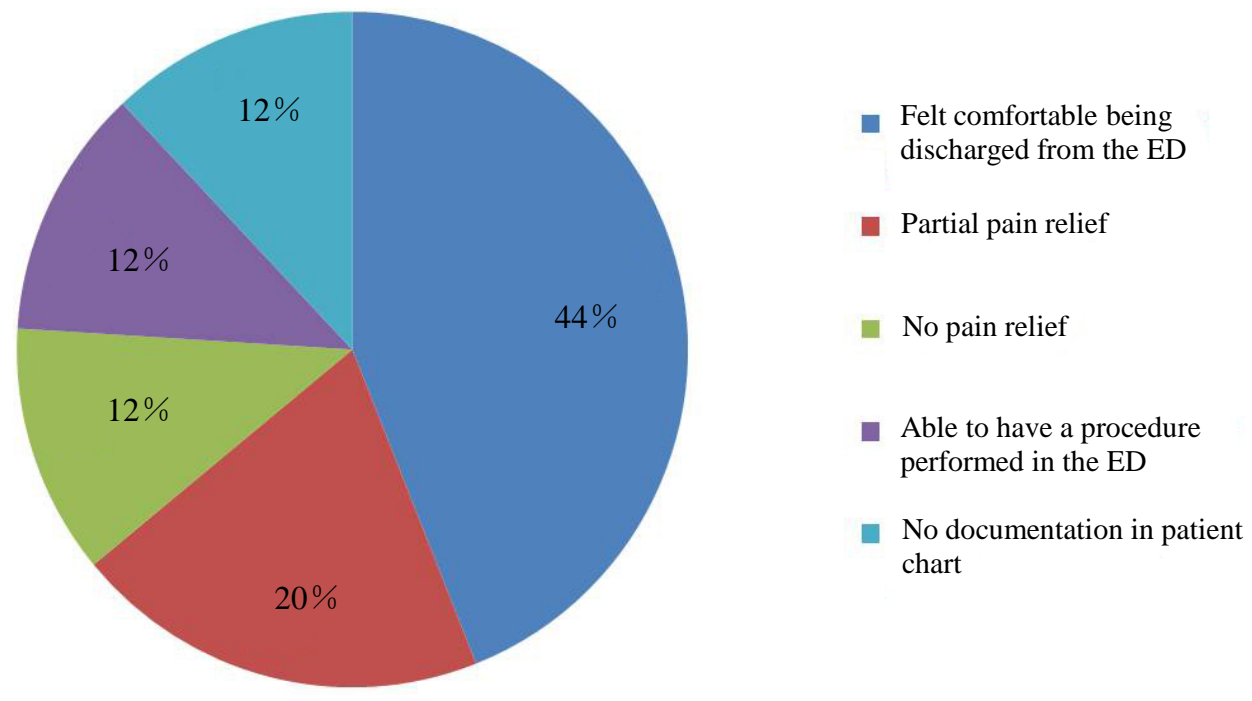

Figure 1. Efficacy data.

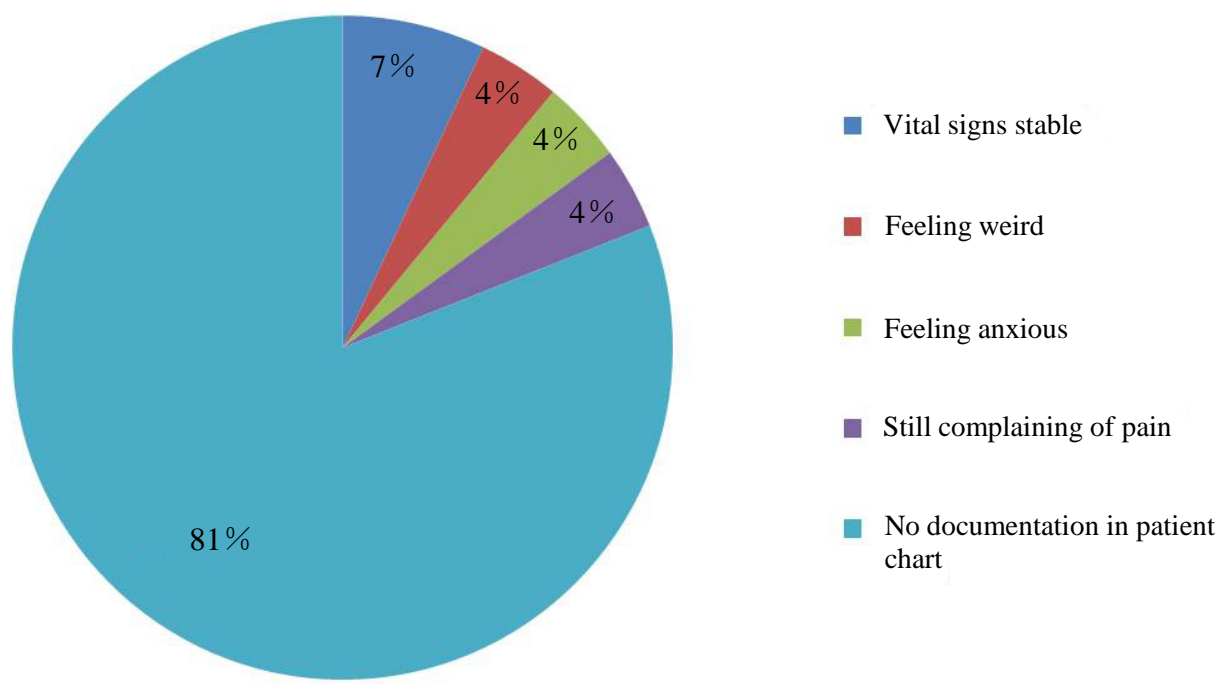

Figure 2. Safety data.

Our study is similar to the study by Beaudoin, et al. in that an improvement in patients' pain scores with minimal adverse events was noted. Our analysis contributes to the literature by further discussing the practice of low-dose ketamine administration at a tertiary academic medical center and describes the prescribing practices at this institution. In our experience, ketamine is not used as a first line agent and is typically used after opioid therapy has been ineffective. The patient population that received ketamine included those who were opioid tolerant. Despite the limited number of patients who received ketamine as a first line therapy, this population may benefit from receiving ketamine as a first line treatment option or earlier in their treatment plan. Our analysis differs from the Beaudoin, et al. since the mean ketamine dose used in our analysis was lower than the ketamine dose used in the Beaudoin, et al. study, which reflects the current practice of our prescribers and may optimize pain control with a lower incidence of adverse effects. Further studies are needed to determine the ideal dose of ketamine.

We acknowledge several limitations in our study; this was a single center, descriptive, retrospective study and has the associated limitations of this design. The retrospective nature of this study may have caused some data to be missed due to inconsistent documentation that was retrospectively reviewed. The sample size is small, and there was inconsistent documentation between the ED Order Entry system and paper medical record documentation and lack of documented safety outcomes. 


\section{Conclusion}

Ketamine, administered at low doses, resulted in an improvement of patients' pain scores while maintaining vital signs. When taking into account the minimal amount of documented adverse outcomes in this patient cohort, ketamine has shown to be a safe and effective option for acute pain relief in the emergency department either as first line therapy or as rescue therapy after opioid administration.

\section{Disclosures}

This research was presented in part at the 2014 Society of Critical Care Medicine’s Annual Congress in Phoenix, AZ.

\section{References}

[1] Pitts, S.R., Niska, R.W., Xu, J. and Burt, C.W. (2008) National Hospital Ambulatory Medical Care Survey: 2006 Emergency Department Summary. National Health Statistics Reports, 2, 1-39.

[2] Weiss, A.J., Wier, L.M., Stocks, C. and Blanchard, J. (2011) Overview of Emergency Department Visits in the United States. HCUP Statistical Brief \#174. Agency for Healthcare Research and Quality, Rockville. http://www.hcup-us.ahrq.gov/reports/statbriefs/sb174-Emergency-Department-Visits-Overview.pdf

[3] Thomas, S.H. (2013) Management of Pain in the Emergency Department. ISRN Emergency Medicine, 2013, Article ID: 583132. http://dx.doi.org/10.1155/2013/583132

[4] Herring, A.A., Ahern, T.L., Stone, M.S. and Frazee, B.W. (2013) Emerging Applications of Low-Dose Ketamine for Pain in the ED. American Journal of Emergency Medicine, 31, 416-419. http://dx.doi.org/10.1016/j.ajem.2012.08.031

[5] Richards, J.R. and Rockford, R.E. (2013) Low-Dose Ketamine Analgesia: Patient and Physician Experience in the ED. American Journal of Emergency Medicine, 31, 390-394. http://dx.doi.org/10.1016/j.ajem.2012.07.027

[6] (2013) Ketamine Package Insert. Hospira, Inc.

[7] Haas, D.A. and Harper, D.G. (1992) Ketamine: A Review of Its Pharmacologic Properties and Use in Ambulatory Anesthesia. Anesthesia Progress, 39, 61-68.

[8] Ahern, T.L., Herring, A.A., Stone, M.S. and Frazee, B.W. (2013) Effective Analgesia with Low-Dose Ketamine and Reduced Dose Hydromorphone in ED Patients with Severe Pain. American Journal of Emergency Medicine, 31, 847851. http://dx.doi.org/10.1016/j.ajem.2013.02.008

[9] (2005) Ketamine Drug Administration Guideline. Brigham and Women’s Hospital. Approved by the Pharmacy and Therapeutics Committee.

[10] Beaudoin, F.L., Lin, C., Guan, S. and Merchant, R.C. (2014) Low-Dose Ketamine Improves Pain Relief in Patients Receiving Intravenous Opioids for Acute Pain in the Emergency Department: Results of a Randomized, Double-Blind, Clinical Trial. Academic Emergency Medicine, 21, 1194-1202. http://dx.doi.org/10.1111/acem.12510

[11] Schmid, R.L., Sandler, A.N. and Katz, J. (1999) Use and Efficacy of Low-Dose Ketamine in the Management of Acute Postoperative Pain: A Review of Current Techniques and Outcomes. Pain, 82, 111-125. http://dx.doi.org/10.1016/S0304-3959(99)00044-5

[12] Ahern, T.L., Herring, A.A., Anderson, E.S., Madia, V.A., Fahimi, J. and Frazee, B.W. (2015) The First 500: Initial Experience with Widespread Use of Low-Dose Ketamine for Acute Pain Management in the ED. American Journal of Emergency Medicine, 33, 197-201. http://dx.doi.org/10.1016/j.ajem.2014.11.010

[13] Sin, B.S., Ternas, T. and Motov, S.M. (2015) The Use of Subdissociative-Dose Ketamine for Acute Pain in the Emergency Department. Academic Emergency Medicine, 22, 251-257. http://dx.doi.org/10.1111/acem.12604

\section{Abbreviations}

ED: Emergency Department.

SD: Standard Deviation.

IQR: Interquartile Range. 